Article

\title{
The Efficiency of the European Non-Life Insurance: CEO Power, Macroeconomic, and Market Characteristics Impact
}

\author{
Walid Bahloul ${ }^{1, *}$ and Abdelfettah Bouri ${ }^{2}$ \\ 1 Governance, Finance and Accounting Laboratory, Faculty of Business and Economics, University of Sfax, \\ Sfax 3018, Tunisia \\ 2 Faculty of Business and Economics, University of Sfax, Sfax 3018, Tunisia; Abdelfettah.bouri@fsegs.rnu.tn \\ * Correspondence: bahloul.walid@gmail.com; Tel.: +216-23-977366
}

Academic Editor: Nicholas Apergis

Received: 21 October 2015; Accepted: 15 January 2016; Published: 1 March 2016

\begin{abstract}
A numbers of studies focusing on the determinant of the insurance market efficiency have increased in the last decade. In fact, many factors, like the CEO's power, can influence the efficiency in the insurance firm. The purpose of this research is to analyze the relationship between efficiency, measured by the cost function using the stochastic frontier approach (SFA) methodologies, and the market structure, as well as the macroeconomic variables. In addition, it focuses on identifying the impact of the integration of the $\mathrm{CEO}$ power variable in the cost function on this relation. The result shows that after the consideration of the CEO power score in the cost efficiency, the relation between insurance efficiency and the determinant of market development, as well as the domestic economy, has changed and become more significant. The result also shows that the firms become more efficient and more profitable with a higher concentration ratio and this is in accordance with the structure-conduct-performance (SCP) theory.
\end{abstract}

Keywords: insurance; efficiency; CEO power; market structure; domestic economy

JEL Classification: G14; G21; G22; G30

\section{Introduction}

There are few studies on the insurance sector that focus on macroeconomics and the market structure effect on the efficiency of the European countries. Therefore, the studies that focus on the determinant of insurance market development have increased in the last decade. In addition, other studies are focused on the relation between competition and efficiency, where competition is in relation with the concentration ratio that can be considered as market specificity. The research in this area started with [1]. He focused on the relation between competition and cost efficiency and found that cost efficiency would decrease if the competition increases. As a matter of fact, many factors can influence the efficiency in the insurance firms. According to [2], the insurance efficiency can be affected by the power of the chief executive officer (CEO). In this paper, Bahloul et al. [2] find that CEO power has a significant effect in the construction of the cost frontier of the insurance sector in the European countries.

The objective of this paper is to analyze the relationship between efficiency, measured by the cost function using the stochastic frontier approach (SFA) methodologies, of non-life insurance implemented in seven European countries, and the market structure and domestic economy. The variable that reflects the market structure is the concentration ratio. The latter represents the market share of the top five non-life insurance premiums for each country and the penetration rate that permits one to identify the 
insurance activity in terms of premium volume as a percentage of GDP in a respective host country and the macroeconomic variable represented by the GDP. Added to that, we will analyze if the integration of the CEO power variable in the cost function can influence the relationship between the insurer's efficiency and the market structure, as well as the macroeconomic variables.

The remainder of this paper is organized as follows: the next section is a literature review of different research that shows the influence of the market and macroeconomic variables on the insurance sector. Section 3 describes our methodology and empirical results. The concluding remarks are drawn in the final section.

\section{Literature Review}

In the insurance literature few studies focus on the relation between efficiency, macroeconomics variables, and market structures. Demsetz [1] focused on the relation between competition and cost efficiency; for this reason he proposed an alternative assumption, also named the efficient-structure-hypothesis. This hypothesis is based on the argument that more efficient industries have lower costs. This allows them to increase their profit. In fact these firms have the ability to capture larger market shares and this results in a high concentration level.

If the firm has superior production or management processes, they can operate at lower costs and realize a higher profit; the efficiency is of $X$-efficiency. This minimum of cost and the higher profits result in higher market shares that grant them a higher market concentration. In the case where the industry produces output levels with minimum average cost, the efficiency here may be in the form of scale efficiency. The firms with the lowest costs, and the resulting higher profits, are considered as operating at optimal economies of scale which permits them to have a higher market concentration.

The relation between competition and efficiency should be an inverse relationship and this is due to the inverse relationship between higher market concentration and competition. In fact, the existence of scale economies in a market means that an increase in the number of competitors results in higher average costs for each incumbent firm. Hence, cost efficiency would decrease if competition increases.

To our best knowledge, the number of empirical studies that test the effects of market structure and macro-economic variables on the efficiency of insurance companies is very narrow. Among the first works that focus on this relation are the papers proposed by Choi and Weiss [3] and Choi and Weiss [4]. They focus on the U.S. property-liability insurance market and the U.S. auto insurance market, respectively. In their paper Choi and Weiss [3] have tested the influence of the market structure on the efficiency of the insurance companies. Choi and Weiss estimate equations in which the scale economies' revenue efficiency and cost efficiency scores are used as independent variables.

Fenn et al. [5] said that the increasing size of the insurance companies within their national markets will permit a degree of local market power that can have different consequences on the insurance efficiency. They also supposed that some recent contributions relating to the banking sector resulted in dramatic changes in the European financial markets [6,7]. Fenn et al. [5] found that, for the specialist firms, the X-inefficiency increases with domestic market share and firm size, but for the composite insurers the degree of $\mathrm{X}$-inefficiency appears to be low, and to vary little with the size.

Kozak [8] focused on the evolution in cost efficiency in the Polish market. He concentrated on the Polish non-life insurance industry over the period between 2003 and 2007. He found that the analyzed period is characterized by intensive restructuring due to the preparation and the first years of operations on the common pan-European financial market. Relatively low density and penetration of insurance services in Poland were important motivations for foreign insurance companies to enter the Polish market. Using the SFA methodology to estimate the cost efficiency Kozak has shown that, over this period, the average level of cost efficiency decreased from $49 \%$ to $43 \%$. To explain and identify the causes of this decline, [8] differentiates between characteristics of insurance companies, the insurance market, and the domestic economy, that may affect the efficiency in the Polish non-life insurance market.

The variable that characterizes the market structure is estimated by the concentration ratio CR-5. It represents the market share of five large insurers, while the annual GDP growth represents the 
macroeconomic conditions of the insurers' operations. Kozak [8] found a positive correlation between the concentration and the efficiency. This results is in accordance with the structure-conduct-performance "SCP theory", which states that the firms become more efficient and more profitable with a higher concentration ratio.

Additionally, the results have shown that non-life insurance cost efficiency is affected by the GDP growth that represents the macroeconomic variables. The correlation between the cost efficiency of Polish non-life insurance market and the GDP growth is negative. The correlation can be explained either by the case that the efficiency in the insurance sectors can be increased by the growing demand for the property and liability protection from individuals and businesses that is in relation with the difficult period in economy, or by the fact that slower GDP growth may reduce the efficiency of the non-life insurance segment due to the reduction of value of durable assets, which has an impact on the values of the gross written premium (GWP) and insurers' earnings.

Choi and Weiss [3] focused on three types of efficiencies: cost efficiency, revenue X-efficiency, and cost scale-efficiency. In this research, the sample is composed by the US auto insurance market. Choi and Weiss based their work on the structure-conduct-performance paradigm and tested the hypothesis that cost efficiency is positively related to concentration in the auto insurance market. Other than the concentration ratio, they focused on the impact of the difference in the regulation in the different states as well as in the market share of each insurance company in each state in the efficiency. According to this hypothesis, cost efficiency should be positively related to concentration. Based on these results, Choi and Weiss [3] found that concentration is positively related to cost X-efficiency, but the coefficient is not quite significant at the $10 \%$ level. Thus, this hypothesis is not identified.

Fenn et al. [5] used data from fourteen European countries and constructed a common European frontier. According to the obtained results, these authors assume that all insurance companies in each European country operate over or below this common frontier. According to this result they also find that, in more concentrated markets, the larger companies are more cost efficient but less revenue efficient.

In addition, [9] use density and penetration as basic measures of global insurance markets connected with the state of the economy. Zhang and Zhu [10] focused on the development of China's insurance sector. They stated that some indicators allow us to measure the development of the insurance industry. Furthermore, the premium volume, the number of insurance policies, or the sums insured that represent the simple method to measure insurance demand, and other such variables are classified as indicators related to socio-economic or macroeconomic variables that are presented by the premium volume, insurance density, and insurance penetration. Thus, in order to contribute to a better understanding of the insurance market, we can use different insurance activity indicators, like world penetration, market share, premiums per employee, or density. The characteristics and structures of the insurance market can be more clearly perceived if these indicators are used.

Arena [11] and Berry-Stölzle et al. [12] use different specific characteristics in each country in their studies. Such a usage allows them to capture a county's market characteristics or economic development. These characteristics are: insurance market concentration, insurance penetration, GDP per capita, credit to private sector, trade openness, corruption index, and stock market turnover (total shares traded to average market capitalization).

Through utilizing data on 456 insurers operating in 50 developing countries over the period between 2004 and 2007, Berry-Stölzle et al. [12] examined the impact of three business strategies, which are diversification, growth, and business mix on the performance of insurance industries. Furthermore, they considered the implications of country-specific effects used by Arena [11] and which they use to capture a county's market characteristics or the economic development on the importance of the three different strategies. In fact, in their analysis they determined which country-specific characteristics contribute to better performance by insurers adopting the three core strategies of diversification, growth, and emphasis on life insurance. Through the diversification strategy of countries that are characterized by lower market competition, higher corruption ratings, and lower trade openness, realize better performance. When the level of insurance penetration is lower, the GDP per capita is higher, and the trade openness is lower, the growth strategy is associated with better performance. 
In a country where the business is focused on life insurance, a better performance is achieved by countries having strong market competition, higher GDP, lower stock market turnover, lower insurance penetration, higher corruption ratings, and lower trade openness.

Finally, to test the efficiency in the European insurance market Bahloul et al. [2] included the CEO power score in the cost efficiency function and prove the importance of $\mathrm{CEO}$ power in the construction of the cost frontier. Henceforth, for this reason we will use in this paper to examine two measures of efficiency and test their relation with the market structure and macroeconomic factors.

\section{Methodology and Empirical Result}

\subsection{Dataset Methodology and Variables Definition}

\subsubsection{Methodology}

In this part, we use different specific characteristics in each country, which allows us to capture a county's market characteristics or the economic development, and that can affect positively or negatively the efficiency scores for each country over the period between 2002 and 2008. For this reason, the econometric efficiency model scores are implemented to the panel regression equation:

$$
Y=f(C R 5, P e n, \operatorname{LnGDP})+\varepsilon
$$

where the independent variable represents efficiency scores, and dependent variables represent the characteristics of the market and domestic economy. The structure of the market is estimated by the CR5 concentration ratio and the Pen penetration rate. The macroeconomic conditions of the insurers' operations are defined by the annual natural logarithm of GDP in each country.

In our work, we differentiate between two types of efficiency estimated by two different models. In these two models, we use the stochastic frontier approach (SFA) methodology which was originally proposed independently by Aigner et al. [13] and Meeusen et al. [14] to estimate the inefficiency for individual insurance.

In the first model we use the Fourier Flexible cost function to estimate the cost efficiency. Under the Fourier Flexible form the model is written as follow:

$$
\begin{aligned}
\ln T C & =\alpha_{0}+\sum_{i=1}^{I} \alpha_{i} \ln Y_{i}+\sum_{n=1}^{N} \beta_{n} \ln P_{n}+\tau_{1} T+\frac{1}{2} \sum_{i=1}^{I} \sum_{i^{\prime}=1}^{I^{\prime}} \delta_{i i^{\prime}} \ln Y_{i} \ln Y_{i^{\prime}} \\
+ & \frac{1}{2} \sum_{n=1}^{N} \sum_{n^{\prime}=1}^{N^{\prime}} \gamma_{n n^{\prime}} \ln P_{n} \ln P_{n^{\prime}}+\frac{1}{2} \tau_{11} T^{2}+\sum_{i^{\prime}=1}^{I^{\prime}} \sum_{n=1}^{N} \rho_{i^{\prime} n} \ln Y_{i^{\prime}} \ln P_{n} \\
+ & \sum_{i^{\prime}=1}^{I^{\prime}} \kappa_{i^{\prime}} T \ln Y_{i^{\prime}}+\sum_{n^{\prime}=1}^{N^{\prime}} \varsigma_{n^{\prime}} T \ln P_{n^{\prime}}+\sum_{q=1}^{N+I}\left[\lambda_{q} \sin Z_{q}+\psi_{q} \cos Z_{q}\right] \\
& +\sum_{q=1}^{N+I} \sum_{r \geqslant q}^{N+I}\left[\lambda_{q r} \sin \left(Z_{q}+Z_{r}\right)+\psi_{q r} \cos \left(Z_{q}+Z_{r}\right)\right]+u+v
\end{aligned}
$$

In the second model, and as in [2], to estimate cost efficiency throughout, we use the following function:

$$
\begin{gathered}
\ln T C=\alpha_{0}+\sum_{i=1}^{I} \alpha_{i} \ln Y_{i}+\sum_{n=1}^{N} \beta_{n} \ln P_{n}+\sum_{k=1}^{K} \theta_{k} \ln D P S_{k}+\tau_{1} T+\frac{1}{2} \sum_{i=1}^{I} \sum_{i^{\prime}=1}^{I^{\prime}} \delta_{i i^{\prime}} \ln Y_{i} \ln Y_{i^{\prime}} \\
+\frac{1}{2} \sum_{n=1}^{N} \sum_{n^{\prime}=1}^{N^{\prime}} \gamma_{n n^{\prime}} \ln P_{n} \ln P_{n^{\prime}}+\frac{1}{2} \sum_{k=1}^{K} \sum_{k^{\prime}=1}^{K^{\prime}} \varepsilon_{k k^{\prime}} \ln D P S_{k} \ln D P S_{k^{\prime}}+\frac{1}{2} \tau_{11} T^{2}+\sum_{i^{\prime}=1}^{I^{\prime}} \sum_{n=1}^{N} \rho_{i^{\prime} n} \ln Y_{i^{\prime}} \ln P_{n} \\
+\sum_{i^{\prime}=1}^{I^{\prime}} \sum_{k=1}^{k} \Gamma_{k i^{\prime}} \ln Y_{i^{\prime}} \ln D P S_{k}+\sum_{i^{\prime}=1}^{I^{\prime}} \ln Y_{i^{\prime}} K T+\sum_{n^{\prime}=1}^{N^{\prime}} \sum_{k=1}^{k} \varphi_{k n^{\prime}} \ln P_{n^{\prime}} \ln D P S_{k} \\
+\sum_{n^{\prime}=1}^{N^{\prime}} \ln P_{n^{\prime}} \zeta T+\sum_{k^{\prime}=1}^{K^{\prime}} \ln D P S_{k^{\prime}} v T+\sum_{q=1}^{N+K}\left[\lambda_{q} \sin Z_{q}+\Psi_{q} \cos Z_{q}\right] \\
+\sum_{q=1}^{N+I+k} \sum_{r \geqslant q}^{N+I+k}\left[\lambda_{q r} \sin \left(Z_{q}+Z_{r}\right)+\Psi_{q r} \cos \left(Z_{q}+Z_{r}\right)\right]+u+v
\end{gathered}
$$


where $\alpha, \beta, \delta, \gamma, \varepsilon, \kappa, \rho, \varphi, v, \Gamma, \psi, \lambda, \theta$, and $\tau$ are coefficients to be estimated. $\ln T C$ is the natural logarithm of total costs. As in the case for [3], the cost variable is defined as the sum of total expenses and the cost of capital. $Y$ is the vector of outputs produced by the producer. In this paper, we use the following as outputs: the non-life insurance losses incurred, the reserves for primary insurance contracts, the reinsurance reserves and the total of investments. $P$ is the vector of input prices presented in our work as the price of labor, price of debt capital, and price of equity capital. $T$ is the time trend variable. DPS represents the CEO power score. This score is calculated by adding 1 to the score whenever one of each criterion is met: the CEO is chair of the board; the CEO is the President; the CEO has the status of a founder; the CEO is the only insider on the board; and the CEO is the only person who signs the letter to shareholders in the annual report. $v_{e}$ is assumed to be distributed as a two-sided normal with zero mean and variance. $\sigma_{\mathrm{v}}$, capturing the effects of the statistical noise. $u_{e}$ is a positive disturbance capturing the effects of inefficiency.

This form is based on the standard translog specification of the cost function complemented with trigonometric terms.

Following [6] and [5], the trigonometric terms of the Fourier flexible form, $Z q$, are used to rescale the input prices and output quantities. As such, each rescaled value is in the interval $[0,2 \pi]$. As in [15], we consider the case when the Fourier flexible forms include two levels of trigonometric terms. Additionally, as in [5], we cut $10 \%$ of each end of the $[0,2 \pi]$ interval to reduce the approximation problems. As such, the rescaled value is comprised in the interval $[0.1 \times 2 \pi, 0.9 \times 2 \pi]$.

As in [5], to calculate the $q^{\text {th }}$ rescaled variables we use the formula $Z_{q}=0.2 \pi-\left(\mu_{L} \times a_{L}\right)+\left(\mu_{L} \times y_{j}\right)$, where $y_{j}$ is the original variable logged, $\mu_{L}=\frac{(0.9 \times 2 \pi)-(0.1 \times 2 \pi)}{b_{L}-a_{L}}$, and $\left[a_{L}, b_{L}\right]$ is the range of $y_{j}$ over the sample.

The restrictions in Fourier flexible form is the same in the translog cost function. In this work as it is the case in [5] and to ensure the linear homogeneity restriction, we divide the total cost variable, the prices of debt capital and the prices of equity capital by the wage rate.

\subsubsection{Dataset and Variables Definition}

We will use the same sample used in [2]; this sample contains information on 125 non-life insurance groups from seven major European countries for the period of eight years between 2002 and 2008. Consistent with the recent literature, we use the modified version of the value-added approach to measure the insurers' outputs and inputs (See [5,16-21]). Based on the above-mentioned authors we can say that there are three principal services, including the risk-pooling and risk-bearing, the real financial services related to insured losses, and intermediation are provided by insurance firms. For this reason, we will use different outputs that can represent good proxies for these services. For instance, the non-life insurance losses incurred represent a good proxy for the amount of risk-pooling and the amount of real services provided. With reference to [17], the real value of the policy reserves represent a good proxy for different services in connection with claims occurring in prior years or claims that are expected to occur in the future. Given that services provided by primary insurers and those provided by reinsurers are different, we make the distinction between the reserves for primary insurance contracts and the real values of reinsurance reserves. The total investments represent the proxy for the intermediation function. To conclude, in this paper we use four outputs: the losses incurred, the reinsurance reserves, the reserves for primary insurance contracts, and the total investments. Focusing on the recent financial literature, four inputs can be identified. They are the labor, the business services, the debt capital, and the equity capital. As in the case of [20], we combine the labor and business services in a single input, which are the operating expenses. These inputs are presented in our work by their prices in the form of three variables: first, the price of labor represents a good proxy for the operating expenses, given that in insurance firms the major expenses are commissions and employees' salaries (See [2]). Second, the one-year treasury-bill rates for each country in the sample on a yearly basis, which represents the proxy for the price of debt capital and that represents an important source 
of funds for insurance companies. Finally, the price of equity capital for each country is expressed as a proxy by the yearly rate of total return on the Stock Exchange Index. According to [3], the cost variable is defined as the sum of total expenses and the cost of capital. Concerning the CEO power measurement, we use the same measures proposed by Liu and Jiraporn [22], in which the CEO power score is calculated by adding one to the score whenever one of each criteria is met: the CEO is chair of the board; the CEO is the President; the CEO has the status of a founder; the CEO is the only insider on the board; and the CEO is the only person who signs the letter to shareholders in the annual report. These different variables are obtained from the proxy statement and annual report. For the price of labor, we consult the ILO October inquiry wage per year, the Eurostat Insurance and pension funding wage per year, the one-year treasury-bill rates for the price of debt capital, and finally the total return on the stock exchange index to the price of equity.

The effect of the integration of the CEO power measurement on the model is generally significant. We use the test of likelihood ratio (LR) that allows us to verify the global significance of our model. The likelihood ratio can be calculated as follow:

$\mathrm{LR}=-2 \times[\ln (\mathrm{H} 0)-\ln (\mathrm{H} 1)]$ where $\ln (\mathrm{H} 0)$ and $\ln (\mathrm{H} 1)$ represent the log-likelihood function of estimated models respectively under the null and alternative hypothesis. We conclude that the likelihood ratio is equal to 70.2 , which is greater than 52.62 , which represents the theoretical value of chi-square at $1 \%$ with a freedom degree equal to 25 .

The results of these two models are summarized in Table 1. Efficiency 1 represents the cost efficiency estimated by the first model and efficiency 2 represents the cost efficiency estimated by the second model.

We note that the efficiency score can be affected by the different characteristics of the market and domestic economy. Referring to the data of European insurance markets published by the CEA (Comité européen des assurances) and the Swiss Re sigma, we construct a balanced sample of 125 non-life insurance groups of seven major European countries for the period of seven years between 2002 and 2008. All insurance data are manually collected. For macroeconomic and market characteristics, we define three variables that, in our assumption, can explain the variation in the efficiency over the period into 2002 and 2007 for each country:

\section{The Gross Domestic Product (GDP)}

The GDP growth represents the total growth in goods and services for each country. The correlation between GDP and efficiency can be explained either by the case that the efficiency in the insurance sector increases through the growing demand for the property and liability protection from individuals and businesses which is in relation with the difficult period in economy, or by the fact that slower GDP growth may reduce efficiency of the non-life insurance segment due to the reduction of value of durable assets, which has an impact on the values of the GWP and insurers' earnings.

\section{The Insurance Penetration Rates}

This measure allows us to identify the insurance activity in terms of premium volume as a percentage of GDP in a respective host country. As such, it measures the significance of the insurance industry in comparison to a host country's total domestic economic activity. It is a useful measure because it is not affected by currency fluctuations as the calculation uses only the national currency of a given host country with respect to both premium income and GDP.

\section{Concentration of the Non-Life Market (CR5)}

This concentration ratio represents the market share of the top five insurance companies in the non-life sector in each European country. The SCP theory states that the firms become more efficient and more profitable with a higher concentration ratio.

The relation between competition and efficiency should be an inverse relationship and this is due to the inverse relationship between higher market concentration and competition. In fact, the existence 
of scale economies in a market means that an increase in the number of competitors results in higher average costs for each incumbent firm. So, cost efficiency would decrease if competition increases.

We make a distinction between two econometric models. The efficiency scores estimated by the two different models are implemented in the panel regression equation. The first is given by the equation:

$$
\text { Eff } 1=f(C R 5, \operatorname{Pen}, \operatorname{Ln} G D P)+\varepsilon
$$

The second panel regression is given by the equation:

$$
E f f 2=f(C R 5, P e n, \operatorname{Ln} G D P)+\varepsilon
$$

Table 1 summarizes the descriptive statistics of each variable defined above. It presents the minimum, the maximum, the mean, and the standard error of used variables. Efficiency 1 is estimated by the first model and Efficiency 2 by the second model. Penetration and concentration rates are expressed in percentage while the macroeconomic variables (LnGDP) are expressed in millions of euros.

Table 1. Descriptive statistics of variables by country. This table presents the minimum, the maximum, the mean, and the standard error of each variable by country. The first line is the min, the second line is the max, the third line is the mean, and the final line is the standard error of each one.

\begin{tabular}{cccccccc}
\hline & SD & BL & UK & NL & FR & SP & GR \\
\hline \multirow{5}{*}{ Efficiency 1 } & 60.53 & 62.32 & 68.18 & 66.74 & 66.05 & 63.45 & 66.97 \\
& 75.29 & 72.27 & 71.74 & 74.71 & 69.06 & 72.80 & 70.57 \\
& 68.76 & 68.06 & 70.02 & 70.95 & 67.87 & 69.62 & 68.49 \\
& 5.310 & 3.210 & 1.404 & 3.067 & 1.204 & 2.934 & 1.467 \\
\hline \multirow{5}{*}{ Efficiency 2 } & 67.91 & 55.62 & 71.26 & 59.72 & 58.69 & 54.75 & 71.49 \\
& 77.71 & 66.50 & 75.31 & 72.04 & 63.40 & 70.06 & 74.12 \\
& 73.33 & 62.33 & 73.68 & 67.17 & 61.80 & 64.43 & 72.63 \\
& 3.583 & 3.700 & 1.294 & 4.239 & 2.010 & 4.719 & 0.934 \\
\hline \multirow{5}{*}{ Poncentration } & 85.22 & 59.10 & 43.90 & 42.80 & 51.70 & 27.80 & 27.90 \\
& 90.80 & 74.10 & 53.20 & 69.94 & 56.00 & 43.94 & 44.72 \\
& 87.89 & 64.00 & 50.01 & 53.94 & 54.10 & 38.58 & 35.35 \\
& 2.140 & 0.058 & 3.293 & 9.703 & 1.716 & 5.936 & 7.204 \\
\hline \multirow{5}{*}{ GDP } & 2.070 & 2.680 & 2.890 & 4.520 & 2.970 & 2.910 & 3.530 \\
& 2.740 & 2.880 & 4.560 & 8.990 & 3.130 & 3.170 & 3.820 \\
& 2.330 & 2.780 & 3.540 & 6.430 & 3.080 & 3.070 & 3.680 \\
& 0.210 & 0.001 & 0.559 & 2.208 & 0.065 & 0.083 & 1.203 \\
\hline & 264,244 & 267,652 & $1,647,056$ & 465,214 & $1,548,634$ & 729,206 & $2,143,180$ \\
& 331,226 & 344,705 & $2,046,535$ & 594,608 & $1,947,440$ & $1,095,163$ & $2,492,000$ \\
& 299,337 & 304,566 & $1,822,259$ & 521,993 & $1,739,528$ & 912,861 & $2,285,354$ \\
& $25,857.4$ & $29,442.2$ & $135,492.3$ & $48,128.0$ & $149,997.2$ & $137,120.9$ & $132,436.9$ \\
\hline
\end{tabular}

In this table, we notice that the higher concentration ratio was achieved by Sweden and the lowest ratio was achieved in Spain. Concentration ratios exceed $40 \%$ outside the German and the Spanish non-life markets. These results indicate significant segmentation in insurance markets, particularly in smaller countries such as Switzerland and the Netherlands, where a few international firms compete globally. The level of insurance development measured by penetration, i.e., the ratio of premiums to GDP is similar in all the sample, except the Netherlands, where the penetration rate in this country exceeds $4 \%$. 


\subsection{Empirical Results}

\subsubsection{Correlation Coefficient}

The goal of the correlation analysis is to measure the technical relation between two variables. This relation is named the correlation coefficient. In our regression, we measure the correlation coefficient between the dependent and the independent variables. Table 2, panel A, summarizes the correlation ratio between Efficiency 1, the concentration ratio, the penetration, and the LnGDP. Table 2, panel B, summarizes the correlation between Efficiency 2 and all other dependent variables. The correlation coefficient is obtained through dividing the covariance between the two variables by the product of their standard deviations.

Table 2. Correlation coefficient between different variable of regression. In this table, panel A presents the correlation coefficient between Efficiency 1, the concentration ratio, the penetration rate, and the LnGDP, and panel B presents the correlation coefficient between Efficiency 2, the concentration ratio, the penetration rate, and the LnGDP.

\begin{tabular}{ccccc}
\hline Panel A & EFF 1 & CR5 & LnGDP & PEN \\
\hline EFF 1 & 1 & & & \\
CR5 & 0.228 & 1 & & \\
LnGDP & -0.087 & -0.450 & 1 & \\
PEN & 0.272 & -0.153 & 0.072 & 1 \\
\hline Panel B & EFF 2 & CR5 & LnGDP & PEN \\
\hline EFF 2 & 1 & & & \\
CR5 & 0.204 & 1 & & \\
LnGDP & 0.129 & -0.450 & 1 & \\
PEN & 0.003 & -0.153 & 0.072 & 1 \\
\hline
\end{tabular}

The correlation is +1 in the case of a perfect positive linear relationship, -1 in the case of a perfect decreasing linear relationship, and between -1 and 1 in all other cases, indicating the degree of linear dependence between variables. The correlation coefficient is 0 if the variables are independent.

These results allow us to find that the level of correlation between all variables used in this regression is generally low.

\subsubsection{Result of Panel Regression}

\section{Result and Discussion}

\section{a. Result of first regression}

To test the effect of the market structure and domestic economy in the efficiency score, we must first choose which is the best model suited to our data. Since our data are based on an unbalanced panel of seven countries, with data averaged over a period of seven year, we therefore use a panel regression. Hence, it is necessary to use the specification test to identify the existence/inexistence of the individual effect. The result is shown in Table 3.

Table 3. Homogeneity test for the first regression.

\begin{tabular}{cccc}
\hline Homogeneity Test & Statistic & d.f & Prob. \\
\hline Cross-section F & 3.178747 & $(6.39)$ & 0.0123 \\
\hline
\end{tabular}

The " $p$-value" of this test is equal to $1.23 \%$, which is lower than $5 \%$. If we focus on Fisher's test, we conclude that the calculated $\mathrm{F}$ is equal to 3.18 , which is greater than 2.34 , the theoretical value for the degree of freedom (6 and 39) at the 5\% level. Thus, the null hypothesis is rejected at the level of five 
percent. Since the null hypothesis of this test is only a common intercept, there is no individual effect on the regression. The null hypothesis is rejected, so we must include individual effects in the model.

The origin of this heterogeneity can be explained by the independent variable. This heterogeneity can be explained by the individual characteristics of the market and domestic economy in each country.

The specification test shows that our theoretical model can be formalized as a panel with individual effects. These effects can be fixed or random. For that, we use the Hausman test, which is a test for determining whether the coefficients of the two estimates (fixed and random) are statistically different. The result of the Hausman test is shown in Table 4. If the theoretical value of chi-squared is greater than the value calculated at $\alpha \%$ with freedom degree $n$ we reject the null hypothesis. In this case, the regression is considered as the model with individual fixed effects.

Table 4. Hausman test for the first regression.

\begin{tabular}{cccc}
\hline Hausman Test & Chi-sq. Statistic & Chi-sq. d.f & Prob. \\
\hline Cross-section Rand & 4.167322 & (3) & 0.2440 \\
\hline
\end{tabular}

In our regression model the " $p$-value" is equal to $24.4 \%$ that is higher than ten percent. Additionally, the theoretical chi-squared at the $10 \%$ level for three degrees of freedom is equal to 0.584, which is lower than the chi-squared calculated value. Thus, we cannot reject the null hypothesis so the best model suited to our data is the model with individual random effect presented in Table 5 . The result in this table represents the estimated coefficient value of market characteristics and domestic economic variables that can affect the efficiency score.

Table 5. Results of the panel regression for the first model. This table represents the estimated coefficient value of market structure (concentration ratio CR-5 and penetration rate), and domestic economic variables (LnGDP) that affect the efficiency score estimated by the first model. Here is the result of the model with individual random effects for a sample with seven countries over seven years.

\begin{tabular}{ccccc}
\hline Variable & Coefficient & Std. Error & $t$-Statistic & Prob. \\
\hline CR5 & 0.046687 & 0.020946 & 2.891613 & $0.0309 * *$ \\
LnGDP & 0.003124 & 0.009116 & 0.342700 & 0.7334 \\
PEN & 0.598435 & 0.383750 & 1.560178 & 0.1257 \\
C & 0.602367 & 0.128494 & 4.687914 & $0.0000^{* * *}$ \\
R-squared & 0.133832 & & Adjusted $R^{2}$ & 0.076087 \\
F-statistic & 2.317650 & & Pr(F-statistic) & $0.088264 *$ \\
Individual Coef. & & & \\
England & 0.006936 & & & \\
Sweeden & -0.001329 & & & \\
Belguim & -0.002082 & & & \\
Netherland & 0.004102 & & & \\
France & -0.018285 & & & \\
Spain & 0.010285 & & & \\
Germany & 0.000372 & & & \\
\hline
\end{tabular}

*** Significant result at the level of $1 \%$; ${ }^{* *}$ Significant result at the level of $5 \%$; Significant result at the level of $10 \%$.

The result in this table represents the panel regression of the efficiency scores on non-life European insurance over the period between 2002 and 2008.

Focusing on the econometric analysis, we find that the model is globally significant at the $10 \%$ level because the probability of the Fischer statistic of this model is equal to $8.83 \%$, which is less than $10 \%$. Only one variable is significant at the level of $5 \%$. The concentration ratio is positive and significant at the $5 \%$ level. Indeed, an increase of the concentration ratio by one percent causes an augmentation of the cost efficiency by $4.67 \%$. 
Our result reveals a positive correlation between concentration and efficiency. This result is in accordance with SCP theory, which states that the firms become more efficient and more profitable with a higher concentration ratio [23].

Due to the inverse relationship between higher market concentration and competition, the cost efficiency would decrease if the competition increases. We can explain this negative relation between cost efficiency and competition by the fact that the existence of scale economies on a market means that an increase in the number of competitors results in higher average costs for each incumbent firm.

b. Result of second regression

In the second regression model, the efficiency is calculated by the integration of the power of the $\mathrm{CEO}$ in the Fourier flexible cost function.

First, to test the existence/inexistence of the individual effect, we use the specification test. The result of this specification test is shown in Table 6.

Table 6. Homogeneity test for the second regression.

\begin{tabular}{cccc}
\hline Homogeneity Test & Statistic & d.f & Prob \\
\hline Cross-section F & 31.402785 & $(6.39)$ & 0.0000 \\
\hline
\end{tabular}

The value of fisher calculated was equal to 31.403 that is greater than 3.30 which is the theoretical $F$-value for the degree of freedom ( 6 and 39 ) at the level of $1 \%$. Thus, the null hypothesis is rejected at the level of one percent. Since the null hypothesis of this test consists of the existence of only one common intercept, there is no individual effect in the regression. The null hypothesis is rejected, so we must include individual effects in the model.

Since the market characteristic represented by the concentration ratio and the penetration and the domestic economic characteristic represented by the LnGDP represent the dependent variables that explain the efficiency, we can explain the heterogeneity by these variables.

Our model can be formalized as a panel with individual effects. To identify if these effects are fixed or random, we use the Hausman test which is a test specifically for determining whether the coefficients of the two estimates (fixed and random) are statistically different. The result of the Hausman test is shown in Table 7.

Table 7. Hausman test for the second regression.

\begin{tabular}{cccc}
\hline Hausman Test & Chi-sq. Statistic & Chi-sq. d.f & Prob. \\
\hline Cross-section Rand & 6.187669 & (3) & 0.1028 \\
\hline
\end{tabular}

The regression model shows that the calculated " $p$-value" is equal to $10.28 \%$, which is higher than ten percent. Additionally, the theoretical chi-squared at the $10 \%$ level for three degrees of freedom is equal to 0.584 , which is lower than the chi-squared calculated value, which is equal to 6.187. Thus, we cannot reject the null hypothesis, and so the best model suited to our data is the model with individual random effects presented in Table 8. The result from this table represents the estimated coefficient value of market characteristics and domestic economic variables that affect the efficiency score.

The result in this table also represents the panel regression of the efficiency scores estimated by the second model on European non-life insurance over the period between 2002 and 2008.

The econometric analysis of the regression shows that the model is generally significant at the level of $5 \%$. Two variables in this regression are significant at the $5 \%$ level. The first significant variable in this regression is the concentration ratio, which is positive and significant at the $5 \%$ level. In fact, an increase of concentration ratio by one percent causes an augmentation of the cost efficiency by $4 \%$. The second significant variable in this regression is the LnGDP. The gross domestic product is also 
positive and significant at the $5 \%$ level, so the efficiency increases by $5 \%$ if the natural logarithm of GDP increases by $1 \%$.

As in the case of the first regression model, the panel regression of the efficiency is estimated by the Fourier flexible cost function including the power of the CEO. The two significant variables are the concentration and the LnGDP. The penetration in this regression has a negative relation with the efficiency and this relation is not significant like in the first regression model. In this regression as it is the case in the first regression, the relation between concentration and efficiency is in accordance with SCP theory. This states that firms become more efficient and more profitable with a higher concentration ratio.

Additionally, the decrease in GDP causes a decrease in efficiency. We can explain this relation by the fact that the diminution in the GDP may reduce efficiency of the non-life insurance segment due to the reduction of value of durable assets, which has an impact on the values of the gross written premium and insurers' earnings. Finally, we note that the relation between efficiency and penetration is not significant.

Table 8. Results of the panel regression for the second model. This table represents the estimated coefficient value of market structure (concentration ratio CR-5 and penetration rate), and domestic economic variables (LnGDP) that affect the efficiency score estimated by the second model. Here is the result of the model with individual random effects for a sample with seven countries over seven years.

\begin{tabular}{ccccc}
\hline Variable & Coefficient & Std. Error & $t$-Statistic & Prob. \\
\hline CR5 & 0.040591 & 0.015644 & 2.594724 & $0.0127^{* *}$ \\
LnGDP & 0.049693 & 0.022641 & 2.194844 & $0.0334^{* *}$ \\
PEN & -0.225866 & 0.381871 & -0.591471 & 0.5572 \\
C & 0.003089 & 0.310087 & 0.009962 & 0.9921 \\
R-squared & 0.158614 & & Adjusted $R^{2}$ & 0.102522 \\
F-statistic & 2.827736 & & Pr(F-statistic) & $0.049082^{* *}$ \\
Individual Coef & & & \\
England & 0.019812 & & & \\
Sweden & 0.078040 & & & \\
Belgium & 0.017964 & & & \\
Netherland & 0.024584 & & & \\
French & -0.086901 & & & \\
Spain & -0.054034 & & & \\
Germany & 0.000535 & & &
\end{tabular}

*** Significant result at the level of $1 \%$; ** Significant result at the level of $5 \% ;{ }^{*}$ Significant result at the level of $10 \%$.

\section{Conclusions}

Despite the implementation of the third generation of insurance directives that were established on 1 July 1994 and gave birth to the single insurance market (SIM) for the European insurance industry, the unification of currency and the creation of the European monetary union raised concerns over international competitiveness among EU insurers. From this starting point, we perceive that the evolution in the determinant of market development and the domestic economy are not the same in different countries used in our sample. Thus, the development of the insurance sector in a country can positively or negatively influence the evolution of efficiency in the country.

Using the panel regression, we analyze the effect of the characteristics of each country's market and the characteristics of their domestic economy in the efficiency evolution over the period between 2002 and 2008. The efficiency was estimated by two models. The first of which is the classical form of the Fourier flexible cost function and the second model includes the power of the CEO. As a result, we find a significant and positive effect of the evolution in the market concentration on the efficiency of the non-life insurance sector. Furthermore, we find a positive and significant relation between the 
LnGDP and the efficiency in the second model. Finally, we note that the relation between efficiency and penetration is not significant for different tested models.

Author Contributions: This paper is written by the author Walid Bahloul and supervised by the author Abdelfettah Bouri.

Conflicts of Interest: The authors declare no conflict of interest.

\section{References}

1. Demsetz, H. Industry Structure, market rivalry and public policy. J. Lawand Econ. 1973, 16, 1-9. [CrossRef]

2. Bahloul, W.; Hachicha, N.; Bouri, A. Modeling the Effect of CEO Power on Efficiency: Evidence from the European Non-Life Insurance Market. J. Risk Financ. 2013, 14, 266-285. [CrossRef]

3. Choi, P.; Weiss, M. An empirical investigation of market structure, efficiency and performance in property-liability insurance. J. Risk Insur. 2005, 72, 635-673. [CrossRef]

4. Weiss, M.A.; Choi, B.P. State regulation and the structure, conduct, efficiency and performance of US auto insurers. J. Bank. Financ. 2008, 32, 134-156. [CrossRef]

5. Fenn, P.; Vencappa, D.; Diacon, S.; Klumpes, P.; O'Brien, C. Market structure and the efficiency of European insurance companies: A stochastic frontier analysis. J. Bank. Financ. 2008, 32, 86-100. [CrossRef]

6. Kraft, E.; Hofler, R.; Payne, J. Privatization, foreign bank entry and bank efficiency in Croatia: A Fourier, flexible function stochastic cost frontier analysis. Appl. Econ. 2006, 38, 2075-2088. [CrossRef]

7. Schure, P.; Wagenvoort, R. Economies of scale and efficiency in European Banking: New evidence. In Economic and Financial Studies Working Paper 99/01; European Investment Bank: Kirchberg, Luxembourg, 1999.

8. Kozak, S. Consolidation and Efficiency of the Non-life Insurance Sector in Poland. Electron. J. Pol. Agric. Univ. 2010, 13, 3 .

9. Bernat, T.; Grundey, D. Insurance Market Maturity: A Comparative Study in Poland and Lithuania. Ukio Technol. Ekon. Vystym. 2007, 13, 184-190.

10. Zhang, C.; Zhu, N. Determinants of the Development of Insurance in China under Globalization. Available online: www.cerdi.org/uploads/sfCmsContent/html/200/Zhang_31.pdf (accessed on 19 February 2016).

11. Arena, M. Does Insurance Market Activity Promote Economic Growth? A Cross Country Study for Industrialized and Developing Countries. J. Risk Insur. 2008, 75, 921-946. [CrossRef]

12. Berry-Stölzle, T.R.; Hoyt, R.E.; Wende, S. Successful business strategies for insurers entering and growing in emerging markets. Geneva Pap. Risk Insur. Issues Pract. 2010, 35, 110-129. [CrossRef]

13. Aigner, D.; Lovell, C.; Schmidt, P. Formulation and estimation of stochastic frontier production models. J. Econom. 1977, 6, 21-37. [CrossRef]

14. Meeusen, W.; van den Broeck, J. Efficiency estimation from Cobb-Douglas production functions with composed error. Int. Econ. Rev. 1977, 18, 435-444. [CrossRef]

15. Altunbas, Y.; Gardener, E.P.M.; Molyneux, P.; Moore, B. Efficiency in European banking. Eur. Econ. Rev. 2001, 45, 1931-1955. [CrossRef]

16. Berger, A.N.; Cummins, J.D.; Weiss, M.A.; Zi, H. Conglomeration versus Strategic Focus: Evidence from the Insurance Industry. J. Financ. Intermed. 2000, 9, 323-362. [CrossRef]

17. Cummins, J.D.; Maria, R.M. Deregulation, Consolidation, and Efficiency: Evidence from the Spanish Insurance Industry. J. Money Credit Bank. 2006, 38, 323-355. [CrossRef]

18. Cummins, J.D.; Weiss, M.A. Analyzing firm performance in the insurance industry using frontier efficiency methods. In Handbook of Insurance Economics; Dionne, G., Ed.; Kluwer Academic Publishers: Boston, MA, USA, 2000.

19. Diacon, S.R.; Starkey, K.; O'Brien, C. Size and efficiency in European long term insurance companies: An international comparison. Geneva Pap. Risk Insur. 2002, 27, 444-466. [CrossRef]

20. Eling, M.; Luhnen, M. Efficiency in the international insurance industry: Across-country comparison. J. Bank. Financ. 2010, 34, 1497-1509. [CrossRef]

21. Hughes, J.P.; Mester, L.J. Bank capitalization and cost: Evidence of scale economies in risk management and signaling. Rev. Econ. Stat. 1998, 80, 314-325. [CrossRef] 
22. Liu, Y.; Jiraporn, P. The Effect of CEO Power on Bond Ratings and Yields. J. Empir. Financ. 2010, 17, 744-762. [CrossRef]

23. Stigler, G.L. A Theory of Oligopoly. J. Polit. Econ. 1964, 72, 44-61. [CrossRef]

(c) 2016 by the authors; licensee MDPI, Basel, Switzerland. This article is an open access article distributed under the terms and conditions of the Creative Commons by Attribution (CC-BY) license (http://creativecommons.org/licenses/by/4.0/). 